\title{
The Impact of Religious and Cultural Beliefs Towards Immunization in Pakistan
}

\begin{abstract}
Eman Anwar, Fawad Saeeduddin, Yasmeen Mahar, Sahal Salman, Rabia Javed
- - - - - - - - - - - - - - - - - - - - - - - - - - -

ABSTRACT:

Pakistan is one of the only two countries in the world where poliomyelitis virus is still not eradicated. Efforts from government such as Expanded Programme on Immunizations (EPI), which has received ample international funding, have not been successful as some sub-sections of population have a negative attitude towards vaccinations. These people generally belong to areas with a lack of education as well as strong influence of religious leaders, who are known to perpetuate misconceptions that the purpose of vaccinations is to sterilize future generations, they are not made from halal products, or are an agenda by Western intelligence agencies to gather information. Also, there are other cultural and social barriers, such as lack of female vaccinators and concerns about their handling. The stance of local people is compared with Muslim leaders and laws of other Islamic countries. Furthermore, a global vaccine confidence survey is discussed to evaluate Pakistan's position in the broader context.
\end{abstract}

Keywords: Expanded Programme on Immunization, Misconceptions, Perceptions, Vaccination, Religious clerics.

How to cite this Article:

Anwar E, Saeeduddin MF, Mahar Y, Salman S, Javed R. .The Impact of Religious \& Cultural Beliefs Towards Immunization in Pakistan J Bahria Uni Med Dental Coll. 2021; 11(2):87-92 DOI: https://doi.org/ 10.51985/AXMH2383

- - - - - - - - - - - - - - - - - - - - - - - - - - - - - This is an Open Access article distributed under the terms of the Creative Commons Attriution Non Commercial Liciense (http:// creativecommons/org/licences/by-nc/4.0) which permits unrestricted non commercial use, distribution and reproduction in any medium, provided the original work is properly cited.

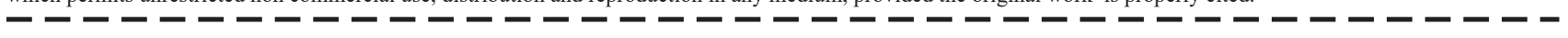

\section{INTRODUCTION:}

Administration of antigenic substance (vaccine) to develop immunity against a disease is known as vaccination. Vaccines offer protection from the harmful effects of diseases by many infectious agents. ${ }^{1}$ Vaccines are a medical breakthrough in the fight against diseases. Two fatal infections, smallpox $^{2}$ and rinderpest (cattle plague) have been globally eradicated as a result. ${ }^{3}$ It is most economical public health interference to protect from communicable diseases and decrease child mortality rate. ${ }^{4}$ Immunization is regarded as one of the most significant health indicators of a thriving childhood. It guarantees safeguard against lethal and crippling childhood

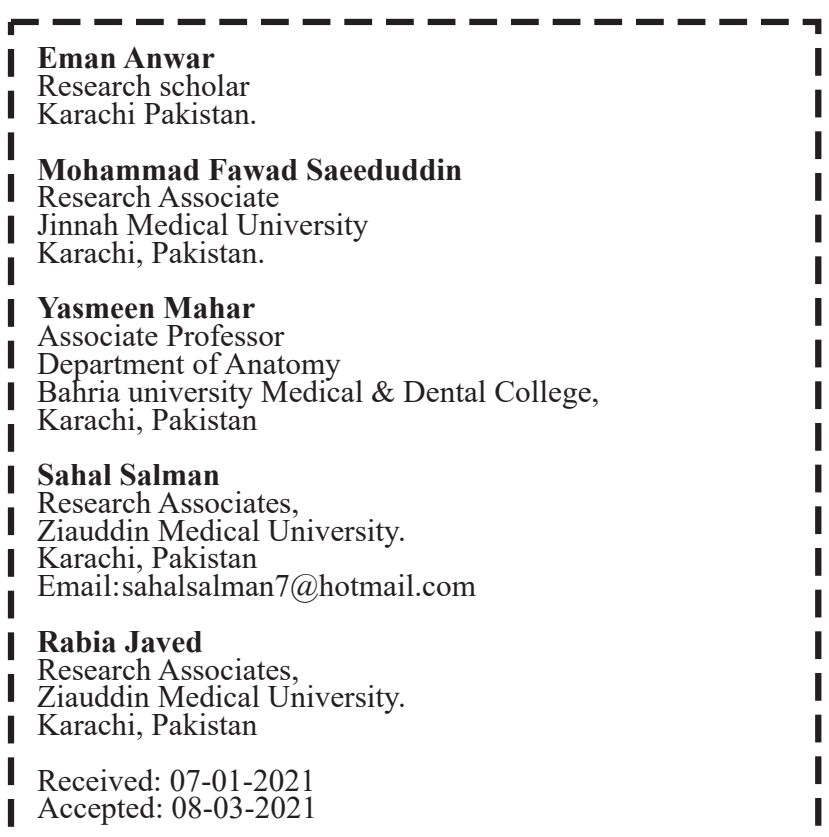

illnesses. ${ }^{5}$ The World Health Organization's Expanded Programme of Immunization was initiated in 1974, with the goal of providing universal access to vaccines to all those at risk. Pakistan's government launched its own Expanded Programme on Immunizations (EPI) in 1978 with the aim of vaccinating children against fatal diseases. The EPI vaccination schedule includes the $B C G$ vaccine against childhood tuberculosis (one dose at birth), the Oral polio virus vaccine (OPV) with 4 doses up till 14 weeks after birth, and vaccines against Diphtheria, Pertussis and Tetanus (DPT) at 6,12 and 14 weeks after birth. The Hepatitis B vaccine was later added to the programme. Along with these immunizations, two doses of measles vaccine are meant to be given to children in Pakistan, at an age of 9 and 15 months. ${ }^{3}$ The aim of this program was to eliminate polio by 2012, eradicate neonatal tetanus and measles by 2015 and to decrease the cases of vaccine-preventable diseases. ${ }^{6}$

The polio eradication programme officially started in $1994 .^{7}$ EPI was implemented with the help of 6000 Lady Health Visitors, 10,000 vaccinators, and other paramedical staff. The polio immunization effort received international funding from the WHO, United Nations Children's Fund (UNICEF), the Bill and Melinda Gates Foundation and the Global Alliance for Vaccinations and Immunizations (GAVI). Although polio cases in Pakistan saw a great decline from 20,000 in the 1990s (UNICEF), the programme was not completely successful in eliminating the virus from the local population, a major cause being people's lack of compliance for vaccinations. ${ }^{3}$

Various reasons can be attributed to the noncompliance of these immunization programs, such as socioeconomic injustice in order to access the services, poor security ${ }^{8}$, 
absence of demographic statistics, poor infrastructure, reduced coverage, attitude of parents, concerns about safety of vaccines, inflow of non-immunized refugees from Afghanistan, insufficient awareness, inefficient training of health care professionals, poor facilities to store vaccine, and finally vaccine quality., 90,11

One of the main causes for the lack of success of immunization programs in Pakistan, Afghanistan and Nigeria is the resistance by Muslim fundamentalists. The religious misconceptions about polio vaccination are one of the biggest hindrances in the tribal areas of Pakistan. Epidemiologists have determined transmittance of polio virus from polioendemic territories, mostly in southern regions of Afghanistan, near the borders of Pakistan to the adjacent tribal areas of Pakistan, which has lead to the emergence of fresh cases of polio in regions which were previously free from polio. In addition to this, Taliban residing in these regions have given verdicts declaring vaccination as an American strategy for sterilization of Muslim populations. Another popular belief propagated by extremists is that vaccination is a way to obviate Allah's will. ${ }^{12}$

\section{METHODOLOGY:}

The literature search included articles from 2000 to 2020. PubMed and Google Scholar were the main search engines utilized, along with JSTOR, using MESH terms vaccine, vaccination, immunization, and religion. After the initial 1546 search results on PubMed, the search was filtered by adding the key word Pakistan, which gave 84 results. Out of these, the articles dealing with social implications or other non-related topics were disregarded and only the ones showing a link between religious, social and cultural beliefs and vaccination were included in the search. From a total of 60 articles read, about 40 were selected for writing this article. Studies from polio virus and measles are mainly included since both diseases are locally prevalent with regular outbreaks every few years.

\section{LITERATURE REVIEW:}

In Pakistan, 5.8 million children under the age of 1 have been enrolled in EPI. ${ }^{13}$ However, even if the first dose is administered, the required subsequent doses are not taken up which renders the schemes ineffective. For instance, only $10 \%$ of children who were given the first dose of DPT from $2000-2004$, completed the entire dosage of vaccination.

One of the most important reasons hindering vaccination against polio virus is the hesitancy of a big section of the masses to immunize their children. This can be attributed to many factors. Pakistani children are given supplemented doses of oral polio vaccine each year which is contrary to WHO recommendation. This raises suspicion in the public due to their lack of awareness of the necessity for booster doses in tropical regions. Moreover, people believe that vaccines are not handled properly during transportation and storage, rendering the vaccine ineffective. ${ }^{14}$ People in Pakistan are also skeptical about the side effects of vaccines due to their improper storage and handling. In an incident in a village in KPK in 2019, a large number of children had to be taken to the hospital due to fainting, vomiting and pain abdomen after they were administered oral polio vaccine. Later on, the enraged protesters burnt a nearby health-care facility. ${ }^{15}$

In 2014, the number of polio cases in Pakistan reached $306^{16}$, causing WHO to declare "a public health emergency of international concern", because of the risk of virus spread to other polio-free countries. ${ }^{17,18,19}$ In response, the government launched the National Emergency Action Plan (NEAP) to curb the spread of the virus. However, progress has been continuously hindered due to a section of the population's reluctance to get vaccinated. Security hazards to the healthcare workers, misguided religious beliefs, and restricted access to conservative communities have gravely impeded the advancement of 'End Polio from Pakistan' campaign. ${ }^{20}$

Region-wise, the areas most influenced by this thinking are conflict zones in Khyber Pakhtunkhwa (KPK). ${ }^{21}$ Federally Administered Tribal Areas (FATA) and some parts of Balochistan. ${ }^{22}$ These districts have a high rate of illiteracy combined with strong influence of religious personalities. The local people place their trust in religious leaders who are unfortunately tend to spread myths and false beliefs regarding immunization campaigns, because of their own lack of comprehensive knowledge. For instance, there is a widespread misconception in some regions of Pakistan, Afghanistan and Nigeria that the polio virus vaccine causes infertility. ${ }^{3}$

A cross sectional study conducted in Peshawar in 2015 revealed a significant association of knowledge about immunizations with the participant's age. Young population seemed to have more knowledge as compared to older individuals. This was most likely due to health information disseminated on different websites on social media. However, it should be understood that the elders in a family are usually the decision makers in society. They make judgement regarding various aspects of life such as whether to vaccinate children in the family. The study also revealed that participants with no formal education, low incomes, who residing in rural localities had little knowledge about diseases such as polio. The results of this study were in accordance to previous reported studies. ${ }^{20}$

Karachi is the only mega city in the world where polio virus still exists. ${ }^{23} \mathrm{~A}$ study conducted in low socioeconomic areas of Karachi revealed that if mothers are provided vaccinerelated targeted knowledge at home, it can improve childhood vaccinate ratio in low literacy areas. A marked betterment was seen in infant DPT-3 and Hepatitis B vaccination in the group of mothers who were provided home-based education on the significance of vaccines, in comparison to those 
Eman Anwar, Fawad Saeeduddin, Yasmeen Mahar, Sahal Salman, Rabia Javed

mothers who were given standard health promotion messages only. ${ }^{24}$ Same holds true for vaccination against other disease such as measles. ${ }^{25}$

Qualitative assessments of a study carried out in three districts of Swat Valley, a region with extensive spread of polio virus, revealed that misinterpretation of religious values is another reason many people refuse vaccines, believing that health and fate are determined by God only. There were false perceptions among residents that oral vaccines contain pork, thus they are not permissible for consumption in Islam. Amongst surveyed districts, the percentage of Lady Health Visitors who faced OPV refusal extended from 0-33\%, while the ratio of mothers who did not want to administer OPV to their young ones ranged from $0.5-5.7 \%$. Their attitude towards injectable vaccines was more or less the same because of the similar reasons. ${ }^{26}$

One of the main factors resulting in non compliance of vaccination is far location of EPI center $(>2 \mathrm{~km})$. Presence of lady health workers in EPI centers was single important factor to have additive outcome in hard to reach areas. ${ }^{27}$ Similarly the lack of female vaccinators in door-to-door campaigns presents cultural barriers for mothers with conservative backgrounds. The repeated administration of OPV has also been cited as a cause for suspicion, as some parents assume that it is meant to ensure their children are sterilized. ${ }^{3}$

A propaganda by religious fundamentalists and militants operating from the Pak-Afghan border has created a story connecting vaccination programmes to a Western conspiracy. It falsely portrays vaccinators as spies for a highly contentious drone programme run by the US Central Intelligence Agency. This belief was reinforced by revelations that the CIA sponsored a phoney hepatitis $B$ vaccination drive to track down Osama Bin Laden in Abbottabad. ${ }^{28}$ For these reasons the campaign has been surrounded by suspicion, particularly in rural KPK and FATA, which have most polio cases as well as the highest refusal rates for vaccine administration. Vaccinators working in such areas of FATA and KPK recount significant hostility, partly since they are considered to be following a Western agenda. Survey data from FATA showed that only $25 \%$ of residents trusted vaccinators compared to $61 \%$ in low-conflict areas, highlighting how pervasive this narrative has become. ${ }^{29}$

Some religious extremists have adopted a hostile approach against immunization teams, endangering their lives. The ban imposed by Taliban on vaccination in 2012 was damaging to the efforts for the eradication of polio, particularly in areas of FATA, where vaccination could not be provided to over 350,000 children for more than two years. ${ }^{17}$ Moreover, targeted attacks against polio frontline workers have killed almost 40 vaccinators since July $2012^{30}$, severely hampering progress and making it harder to recruit health care workers for the campaign. These incidents are not only limited to conflict-affected areas, for on July 2012, an anti-polio worker was attacked in Islamabad. The next day, a UN doctor was shot in Karachi. ${ }^{31}$

A study of religious scholars' awareness and attitudes towards polio immunization of Muslim scholars from religious institutions and local mosques were surveyed using anonymous and self-administered questionnaires. About $45.2 \%$ of participants displayed good knowledge about polio. There were knowledge gaps in $32.6 \%$ of them regarding modes of transmission, and in $39.9 \%$ about consequences of polio virus. Overall, $68.4 \%$ of participants displayed a positive attitude towards polio immunization. Nonetheless, $44.6 \%$ showed reservations about participating in future polio immunization campaigns. $75 \%$ quoted security and $64 \%$ vaccine management issues as the leading hurdles towards immunization of polio in Pakistan. Upon evaluation, results depicted insufficient knowledge of the scholars about polio, even though more than half had a positive attitude towards immunization. Further research is needed at the national level for more valid results. ${ }^{12}$

However, in 2013, Maulana Samiul Haq, head of the political party "Jamiat Ulema-e-Islam" declared a fatwa that "there is nothing forbidden" in the polio vaccine, at his Darul Uloom Haqqania religious seminary located in the city of KPK, Akora Khattak. He further stated that it is the duty of the religious scholars who are present in Ulema councils to eliminate misinterpretations about the usage of vaccines in order to safeguard the children from the incapacitating illness. He also publicly announced that Shari'a law in Islam states clearly that this is the responsibility of the people to get their children vaccinated. ${ }^{32}$

Attitude of people towards other vaccinations is also poor. Measles, a fatal disease which claimed the lives of 300 children in Pakistan in $2012^{33}$, still has insufficient immunization coverage due to some people's lack of awareness and reluctance towards vaccines. Another outbreak occurred in 2017, in which 130 children died. The number of deaths rose to 300 in the first eight months of $2018 .{ }^{34}$ The first measles-containing vaccine (MCV1) dose had a nationwide coverage of $76 \%$ in 2017 , well below the recommended level of $95 \% .^{35}$

During the measles outbreak of 2012, vaccination teams in rural areas of Sindh faced much resistance from parents. According to a news report by The Express Tribune, the villagers were adherents of Hindu beliefs which declare that a goddess had entered the affected children and medicine would offend her. Some songs were even chanted to the child. These customs prevented parents from seeking proper medical treatment for their children suffering from measles. Earlier, parents in Khairpur district believed measles was a test of faith and refused medical help for the disease. ${ }^{36}$

If we compare these perspectives to a qualitative study of religious and community leaders' acceptance of rotavirus 
vaccine in Yogyakarta, Indonesia, a different attitude is observed. Rotavirus is a disease which causes diarrhoea in young children and can potentially be fatal. The oral rotavirus vaccine in Indonesia is not funded through the National Immunization Programme (NIP), nor does it have halal labeling by Indonesia's Islamic Council due to the use of porcine trypsin in its manufacture. Therefore its acceptance by religiously racticing Muslims in Indonesia is complex. In this study, a series of interviews with community leaders and community representatives were carried out. The results showed that the leaders were broadly accepting of the vaccine and recognized their role in promoting it in their communities. $^{37}$

It is worth noting that the behavior of such religious authorities is not always consistent with their stance. The Meningococcal vaccine has long been among the Hajj mandated vaccines for pilgrims all over the world. ${ }^{38}$ All the religious leaders who project a negative stance towards immunization must have been vaccinated themselves during their holy visits to Saudi Arabia. More recently, the polio virus vaccine was also made mandatory for pilgrims arriving from Pakistan. Common Muslims who follow these clerics must be made aware of their double standards to change their attitudes towards immunization programmes.

\section{Comparison with vaccine attitudes worldwide:}

A global survey of 67 countries, including Pakistan, assessed overall vaccine confidence and identified patterns interviewing by 65,819 respondents, it examined their perceptions of vaccine safety, religious compatibility, importance and effectiveness. Religious factors displayed no consistent pattern on the global scale, though the Western Pacific region recorded the greatest level of religious discordance with vaccines. Faith-compatibility issues were observed in many countries, most notably Mongolia and Thailand. Although religious fundamentalism seems to be the leading factor for the refusal of polio vaccine in Pakistan, Afghanistan and Nigeria, which showed objection to vaccines due to religious beliefs $(14 \%, 12 \%$ and $3 \%$ respectively), but faith is not the only factor linked to it, e.g., Saudi Arabia, a country with $100 \%$ Muslim respondents, showed minimal religious resistance rate (2\%). It has been noted in a review on vaccination and religious instructions, that most vaccine hesitation and rejection, which are thought to be due to religious faith, is more connected to the safety of the vaccine or personalized reasons which are disseminated within religious groups across social networks. Historical, cultural and political circumstances alter the effect of religion rather than being specifically connected to theological idea. ${ }^{39,40}$

It is recommended that vaccine awareness campaigns should work within the existing belief system. In order to eradicate vaccine preventable diseases, it is imperative to engage religious community leaders in raising awareness and changing parents' perceptions towards vaccinations. Enlisting their support for the campaign will impact the mindset of countless people under their influence. Dispelling common myths and clearing doubts about the quality of vaccines would be further steps in the right direction. Approaching the campaign from a religious point of view, religiously observant Muslims should be made to understand that treating preventable diseases is encouraged in Islam. They should be made aware how immunization programmes are implemented in other Muslim majority states, such as the strictly religious Saudia Arabia.

Parental perception is vital for the success of immunization campaigns, and the education of the mother has been linked to their level of acceptance of vaccines. Thus female literacy should be made a higher priority. The number of female vaccinators should also be increased to comply with social and cultural values for mothers who might be alone with their children.

At this hour, it is crucial to improve the attitude of people towards vaccines, because a possible vaccine against COVID19 could be the only permanent way to counter the pandemic. Given the highly communicable nature of the disease, the people of Pakistan must not let their beliefs and misconceptions stand in the way of not only their own health, but the health of those around them.

\section{CONCLUSION:}

The research establishes that vaccine resistance is mainly based on religious, cultural and social grounds. However, religion is not the only factor as Muslims in other countries have a far more accepting approach, rather it is the way religion is interpreted due to cultural norms. Anti-western sentiment plays a key role as well, raising suspicions about vaccination campaigns and their links to US intelligence services. Repeated doses, doubts about the effectiveness of vaccines, lack of female vaccinators and fabricated myths are other obstacles in the success of immunization campaigns. The general lack of trust towards frontline health workers has created a hostile environment for them, raising concerns for their safety. Media coverage of such incidents gives the country a negative reputation internationally. Worldwide, religious factors are not as prominent as other concerns about vaccine safety and effectiveness. As a result of these perceptions, the health care system's struggle is not against medically curable diseases, but misguided beliefs.

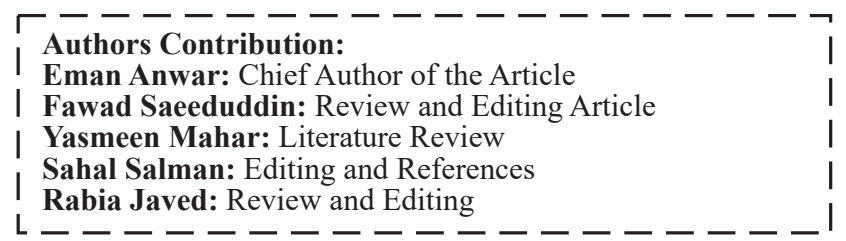

\section{REFERENCES:}

1. Lorenz C, Khalid M.Influencing factors on vaccination uptake in Pakistan. J Pak Med Assoc. 2012; 62 (1): 59-61 
2. Closser S. "We Can't Give Up Now": Global Health Optimism and Polio Eradication in Pakistan, Medical Anthropology. 2012; 31(5): 385-403, DOI: 10.1080/01459740.2011.645927

3. Hussain SF, Boyle P, Patel P, Sullivan R. Eradicating polio in Pakistan: an analysis of the challenges and solutions to this security and health issue". Globalization and Health. 2016; 12(1):2-9. doi: 10.1186/s12992-016-0195-3.

4. Sahito A, Ahmed S, Fatmi Z. Covering the last mile for vaccination: Feasibility and acceptability of traditional birth attendant-based referral system in hard-to-reach areas in rural Pakistan. Journal of Global Health. 2020; 10(2), 1-9. doi: 10.7189/jogh.10.021303

5. Bugvi AS, Rahat R, Zakar R, Zakria MZ, Fischer F, Nasrullah $\mathrm{M}$, et al. Factors associated with non-utilization of child immunization in Pakistan: evidence from the Demographic and Health Survey 2006-07. BMC Public Health. 2014; 14 (232):2-7. https://doi.org/10.1186/1471-2458-14-232

6. Baloch MN, Siddiqui NZ, Bano A, Siddiqui S, Kiran, T, Khan MK, et al. A cross sectional survey: Attitude towards adult vaccination in Karachi-Pakistan. International Journal of Advanced Research. 2015; 3 (3): 512-52

7. Alexander JP, Zubair M, Khan M, Abid N, and Durry E. Progress and Peril: Poliomyelitis Eradication Efforts in Pakistan, 1994-2013. Journal of Infectious Diseases, 2014; 210 (suppl 1): S152-S161. doi: 10.1093/infdis/jiu450.

8. Owais A, Khowaja AR, Ali SA, Zaidi AKM. Pakistan's expanded programme on immunization: an overview in the context of polio eradication and strategies for improving coverage. Vaccine. 2013;31(33):3313-19

9. Niazi AK, Sadaf R. Editorial; Measles Epidemic in Pakistan: In Search of Solutions. Annals of medical and health sciences research. 2014;4(1):1-2.

10. Husain S, Omer SB. Routine immunization services in Pakistan: seeing beyond the numbers. East Mediterr Health J, 2016;22(3):201-11. doi: 10.26719/2016.22.3.201. PMID: 27334077.

11. Kols A, Gorar Z, Sharjeel M, Midhet F, Nazir R, Kumar D, et al. Provincial differences in levels, trends, and determinants of childhood immunization in Pakistan. East Mediterr Health J, 2018;24(4):333-44. https://doi.org/10.26719/2018.24.4.333

12. Khan MU, Ahmad A, Salman S, Ayub M, Aqeel T, Haq N, et al. Muslim Scholars' Knowledge, Attitudes and Perceived Barriers Towards Polio Immunization in Pakistan. Journal of Religion and Health. 2017; 56(2): 635-48. doi: 10.1007/s10943016-0308-6.

13. Butt M, Muhammad R, Butt E, Butt S, Xiang J. Why Have Immunization Efforts in Pakistan Failed to Achieve Global Standards of Vaccination Uptake and Infectious Disease Control? Risk Management and Healthcare Policy. 2020;13: 111- 24. DOI: https://doi.org/10.2147/RMHP.S211170

14. Ali M, Ahmad N, Khan H, Ali S, Akbar F, Hussain Z. "Polio vaccination controversy in Pakistan", The Lancet. 2019; 394(10202): 915-16. doi: 10.1016/s0140-6736(19)32101-4.

15. Pakistan Today. Protesters burn health unit in Peshawar over polio vaccine. https://www.pakistantoday. com.pk/2019 /04/22/polio-vaccination-drive-in-peshawar-triggerscontroversy/ Date: April 22, 2019

16. Mohiuddin H, Godil A, Hafiz MY. Triumph over adversity: Pakistan's successes against polio. Lancet Glob Health. 2017;5(1):e38.
17. Basharat $\mathrm{S}$, Shaikh BT. Polio immunization in Pakistan: ethical issues and challenges. Public health reviews. 2017;38(1):16. doi: 10.1186/s40985-017-0049-4

18. Mushtaq A, Mehmood S, Rehman MA, Younas A, Rehman MS, et al. Polio in Pakistan: Social constraints and travel implications. Travel Med Infect Dis. 2015;13(5):360-6.

19. Garon JR, Orienstein WA. Overcoming barriers to polio eradication in conflict areas. Lancet Infect Dis. 2015;15(10):1122-4.

20. Khan MU, Ahmad A, Aqeel T, Salman S, Ibrahim Q, Idrees $\mathrm{J}$, et al. Knowledge, attitudes and perceptions towards polio immunization among residents of two highly affected regions of Pakistan. BMC public health. 2015;15(1):1-8. https://doi.org/10.1186/s12889-015-2471-1

21. Kennedy J, McKee M, King L. Islamist insurgency and the war against polio: A cross-national analysis of the political determinants of polio. Globalization and health. 2015;11(1):19. https://doi.org/10.1186/s12992-015-0123-y

22. Khan S, Qureshi MSH. Poliomyelitis Eradication in Pakistan: Successes \& Failures. Journal of Saidu Medical College 2018. 8(2): 198-202

23. Siddiqui NT, Owais A, Agha A, Karim MS, Zaidi AKM. Ethnic disparities in routine immunization coverage: A reason for persistent poliovirus circulation in Karachi, Pakistan? Asia Pac J Public Health. 2014;26(1):67-76

24. Owais A, Hanif B, Siddiqui AR, Agha A, Zaidi AK. Does improving maternal knowledge of vaccines impact infant immunization rates? A community-based randomizedcontrolled trial in Karachi, Pakistan. BMC public health. 2011;11(1):1-8.

25. Crocker-Buque1 T, Mindra G, Duncan R, Mounier-Jack S. Immunization, urbanization and slums - a systematic review of factors and interventions. BMC Public Health. 2017; 17(556):1-16. DOI 10.1186/s12889-017-4473-7

26. Murakami H, Kobayashi M, Hachiya M, Khan ZS, Hassan SQ, SakuradaS. Refusal of oral polio vaccine in northwestern Pakistan: A qualitative and quantitative study. Vaccine. 2014; 32(12):1382-7.

27. Khowaja AR, Zaman U, Feroze A, Rizvi A, Zaidi AKM. Routine EPI Coverage: Subdistrict Inequalities and Reasons for Immunization Failure in a Rural Setting in Pakistan. AsiaPacific Journal of Public Health. 2015; 27(2): NP1050-NP1059

28. Shah SFA, Ginossar T, Weiss D. "This is a Pakhtun disease": Pakhtun health journalists' perceptions of the barriers and facilitators to polio vaccine acceptance among the high-risk Pakhtun community in Pakistan. Vaccine. 2019; 37(28): 3694 -703. doi: 10.1016/j.vaccine.2019.05.029. Epub 2019 May 30. PMID: 31155417.

29. SteelFisher GK, Blendon RJ, Guirguis S, Brulé A, LasalaBlanco N, Coleman M, et al. "Threats to polio eradication in high-conflict areas in Pakistan and Nigeria: a polling study of caregivers of children younger than 5 years". The Lancet Infectious Diseases. 2015;15(10): 1183-92. doi: 10.1016/s14733099(15)00178-4.

30. Ghafoor, S., \& Sheikh, N. Eradication and Current Status of Poliomyelitis in Pakistan: Ground Realities. Journal of Immunology Research. 2016: 1-6. doi:10.1155/2016/6837824

31. Fatima K, Qadri I. View of Battle against poliovirus in Pakistan. J Infect Dev Ctries. 2013; 7(11):897-9. doi:10.3855/jidc. 3647 
The Impact of Religious and Cultural Beliefs Towards Immunization in Pakistan

32. R, Ahmad Ullah A. We Believed Our Cleric': Pakistani Polio Victim's Regretful Father Urges Others To Use Vaccine December 12, 2017 15:16 GMT

33. Measles - Expanded Program on Immunization, Pakistan (2020). Available at: http://www.epi.gov.pk/vaccinepreventable-diseases/measles/

34. Curbing measles (2019). Available at: https://www.dawn.com/news/1520931 .

35. Mere MO, Goodson JL, Chandio AK, Rana MS, Hasan Q, Teleb N, et al. "Progress Toward Measles Elimination Pakistan, 2000-2018". Morbidity and Mortality Weekly Report，2019; 68(22):505-510. doi: 10.15585/mmwr.mm6822a4.

36. Measles outbreak in Sindh: More than 30 children died in 20 days | The Express Tribune (2012). Available at: https://tribune.com.pk/story/483201/measles-outbreak-insindh-more-than-30-children-died-in-20-days
37. Padmawati RS, Heywood A, Sitaresmi MN, Atthobari J, MacIntyre CR, Soenarto Y, et al. Religious and community leaders' acceptance of rotavirus vaccine introduction in Yogyakarta, Indonesia: a qualitative study. BMC Public Health, 2019;19 (1), 368,1-6. https://doi.org/10.1186/s12889-0196706-4

38. Al-Tawfiq J, Memish Z. "The Hajj 2019 Vaccine Requirements and Possible New Challenges", Journal of Epidemiology and Global Health. 2019;9(3): 147-152. doi: 10.2991/jegh.k. 190705.001

39. Larson HJ, de Figueiredo A, Xiahong Z, Schulz WS, Verger P, Johnston IG, et al. The State of Vaccine Confidence 2016: Global Insights Through a 67-Country Survey. E Bio Medicine, 2016; 12: 295-301. doi: 10.1016/j.ebiom.2016.08.042.

40. Kennedy J. Why have the majority of recent polio cases occurred in countries affected by Islamist militancy? A historical comparative analysis of the political determinants of polio in Nigeria, Somalia, Pakistan, Afghanistan and Syria. Med Confl Surviv. 2016;32(4):295-316. 